\title{
Hemireplacement Arthroplasty with Unipolar vs Bipolar Prosthesis for Displaced Hip Fractures in Elderly
}

\author{
Dutta D, ${ }^{1}$ Bajracharya $A R^{1}$ \\ 'Department of orthopedics, Bir Hospital, NAMS.
}

\section{ABSTRACT}

Background: Hip fractures are common occurrence in elderly with various methods of treatment practiced for its management. Hemireplacement with different types of prosthesis is most widely practiced, and cemented bipolar prosthesis being the current trend. The aim of this study is to compare the outcome of unipolar prosthesis which is the current practice at our hospital, with the bipolar prosthesis.

Methods: This was a prospective study patients aged over 65 years with displaced femoral neck or trochanteric fracture underwent hemireplacement arthroplasty, cemented unipolar prosthesis was used in 18 patients and in 16 bipolar prosthesis was used. Functional outcome using Harris Hip Score and mobility score was compared between two groups.

Results: The two groups of patients did not differ in their pre-injury characteristics (age, sex, fracture pattern, ASA grading, co-morbidity, mode of injury and pre-injury ambulatory status) and peri-operative parameters such as duration of operation, blood loss, hospital stay. One year after operation, there was no statistical difference in the functional parameters such as Harris Hip Score, mobility score and rate of complication in both the groups.

Conclusions: Early results suggest that Cemented unipolar prosthesis are equally effective as compared to bipolar for the treatment of displaced hip fractures in elderly patients, in Nepalese context.

Key words: hip fracture, hemiarthroplasty, harris hip score.

\section{INTRODUCTION}

Hip fractures are common injuries which results in high morbidity and mortality in elderly patients. The goal of management of hip fractures in elderly patients is to mobilize them early to avoid complications of recumbency. With improvement in National health care geriatric population in Nepal is also increasing, so is the hip fracture. This has an increased cost burden to the nation for their treatment. Hence, to save cost it becomes necessary to find less expensive ways to treat them. So this study was carried out.
The theoretical advantage of bipolar over unipolar prosthesis is the reduction of acetabular erosion due to movement at two poles causing less movement at prosthetic head and acetabulum. ${ }^{1}$ The same mechanism is described for less pain during locomotion. Use of bipolar arthroplasty, however has been challenged by studies mentioning that shortly after implantation, the motion at the inner bearing ceases, converting the prosthesis to a unipolar implant. ${ }^{2-5}$

The aim of this study is to compare the functional results of cemented unipolar and bipolar hemiarthroplasty in the

Correspondence: Dr. Deepak Dutta, Bir Hospital, NAMS, Mahaboudhha, Kathmandu, Nepal. Phone: 9741078070, Email: dr.deepakdutta@gmail.com 
Hemireplacement Arthroplasty with Unipolar vs Bipolar Prosthesis for Displaced Hip Fractures in Elderly

treatment of displaced femoral neck and trochanteric hip fractures in elderly Nepalese population as their cost are strikingly different.

\section{METHODS}

A prospective comparative study was conducted orthopaedic departments of Bir Hospital from March 2005 to March 2009. The ethical approval and patient consent was taken. The patient with older than 65 years with displaced femoral neck or trochanteric fracture and those falling in ASA (American Society of Anesthesiologist) grade II, III and IV were included in the study. Undisplaced femoral neck, subtrochanteric, pathological and open fractures was excluded. Patients were allocated alternately to the unipolar or bipolar group. Demographic and prosthetic data were recorded in performa. All patients received preoperative antibiotics (Inj Ceftriaxone 1 gram IV) before the administration of either spinal or general anesthesia and continued for 5 days intravenously and Cloxacillin orally for 7 days then after. All hemiarthroplasties were performed through Hardinge's direct lateral approach, wound closure were performed in layers over 2 suction drains, superficial and deep, which were removed on second and third post-op day respectively. Post-operative ambulation was initiated on second postoperative day after removal of superficial drain, using walking aids. Weight bearing was allowed according to patients comfort. The occurrence of a postoperative complication, the length of hospitalization, and the cost of the prosthesis were recorded. Postoperative follow up examinations were performed at 6 weeks, 3 months, six months and 12 months. Harris Hip Score and mobility score was recorded in each follow up along with physical and radiographic examination of the affected hip. Statistical analysis and data entry were done by using Statistical Package for Social Science (SPSS) version 13 for windows.

\section{RESULTS}

Thirty four patients with cemented hemiarthroplasty were enrolled in this study, 18 in unipolar group and 16 in bipolar group. Three patients in unipolar and one patient in bipolar group lost in follow up, so 15 patients in each group were available for final analysis. Although the mean age of patient in bipolar group (78.67 years) was higher than unipolar group (74.13 years) it was statistically insignificant $(P=0.66)$. There were no statistically significant differences between the groups in terms of gender, fracture pattern, medical comorbidities, or preoperative ambulatory status (Table 1 ). Differences between the groups with respect to estimated blood loss, and length of stay, operative delay, operative

Table 1. Pre and post-operative data of the Study Groups

\begin{tabular}{|c|c|c|c|}
\hline Patient Demographics & Unipolar & Bipolar & P-value \\
\hline Age (years) & 74.13 & 78.67 & 0.66 \\
\hline \multicolumn{4}{|l|}{ Gender } \\
\hline Male & $4(27 \%)$ & $6(40 \%)$ & \\
\hline Female & $11(73 \%)$ & $9(60 \%)$ & \\
\hline \multicolumn{4}{|l|}{ Fracture pattern } \\
\hline Neck of femur & $46.7 \%$ & $46.7 \%$ & \\
\hline Intertrochanteric & $53.3 \%$ & $53.3 \%$ & \\
\hline \multicolumn{4}{|l|}{ ASA Grade } \\
\hline II & $8(53 \%)$ & $9(60 \%)$ & \\
\hline III & $5(33.3 \%)$ & $6(40 \%)$ & \\
\hline IV & $2(13.3 \%)$ & - & \\
\hline Comorbid disease & $70 \%$ & $66.7 \%$ & $>0.05$ \\
\hline Preinjury Ambulatory status & 5.33 & 4.93 & 0.145 \\
\hline Operative delay(in days) & 11 & 13.87 & 0.326 \\
\hline Hospital Stay(in days) & 25.13 & 24.33 & 0.299 \\
\hline Operative duration(min) & 68 & 67.33 & 0.837 \\
\hline Intraoperative blood loss & $146.67 \mathrm{ml}$ & $150 \mathrm{ml}$ & 0.789 \\
\hline MASM at 12 months & 5.07 & 4.2 & 0.229 \\
\hline Harris hip score at 12 months & 85.40 & 85.20 & 0.975 \\
\hline
\end{tabular}


Hemireplacement Arthroplasty with Unipolar vs Bipolar Prosthesis for Displaced Hip Fractures in Elderly

time were also statistically insignificant (Table 1). The mean MASM at 12 month in unipolar group was 5.07 in comparision to 4.2 in bipolar $(P=0.229)$. Similarly Harris hip score between two groups were also not significantly different. Six patient in unipolar and 7 in bipolar group were indoor ambulator at final follow up (Figure 2). At 12 month follow up, 13 out of 14 patients in unipolar group had good to excellent Harris hip rating in comparison to 12 out of 14 in bipolar group (Figure 3 ).

\section{DISCUSSION}

Specific designation of the inclusion and exclusion criteria, has enabled us to study a more or less homogeneous group of patients. The two groups of patients in our study did not differ in their pre-injury characteristics, peri-operative parameters such as duration of operation, blood loss and hospital stay and functional parameters such as Harris Hip Score and mobility at 12 months follow up. Several studies have been published reporting similar finding to our study. ${ }^{6-8}$ Cornell et al. performed a prospective six month follow-up of thirtythree bipolar and fifteen unipolar hemiarthroplasties and found no differences in postoperative complication rates, length of hospitalizations, or hip rating outcomes between the two groups of patients. ${ }^{6}$ Hudson et al., in an eight-year retrospective review of ninety unipolar and forty-eight bipolar hemiarthroplasties, showed no statistically significant differences in the rates of mortality, surgical complications, or other events including medical complications. ${ }^{7}$ In our study, one patient from each group died, one because of renal failure and in other patient the exact cause was not known. Calder et al., in a randomized, prospective two-year trial comparing cemented unipolar and bipolar prosthesis in octogenarians, found no difference between the rate of complications and survival time. ${ }^{8}$ although we have not measured pain scale in our cases, Kenzora et al, in a prospective outcome study at twentyfour months follow-up of 195 bipolar and seventy-five unipolar hemiarthroplasties, showed that patients who underwent bipolar hemiarthroplasty had better pain relief and function. ${ }^{9,10}$

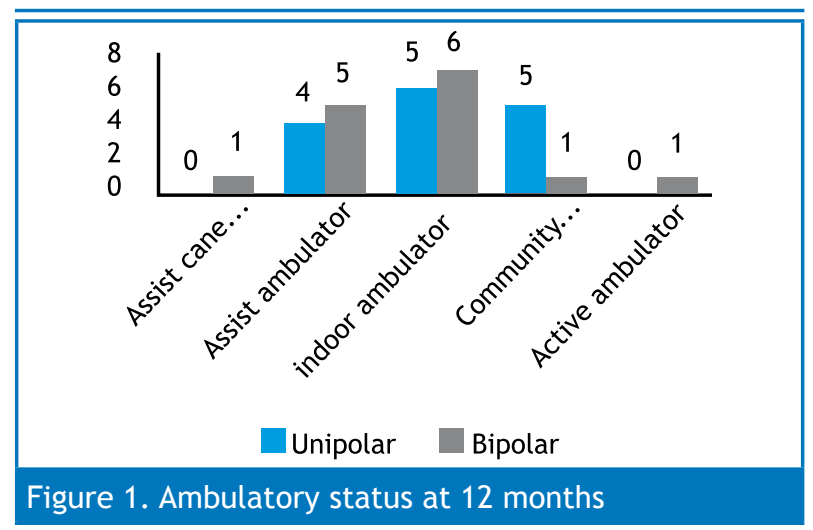

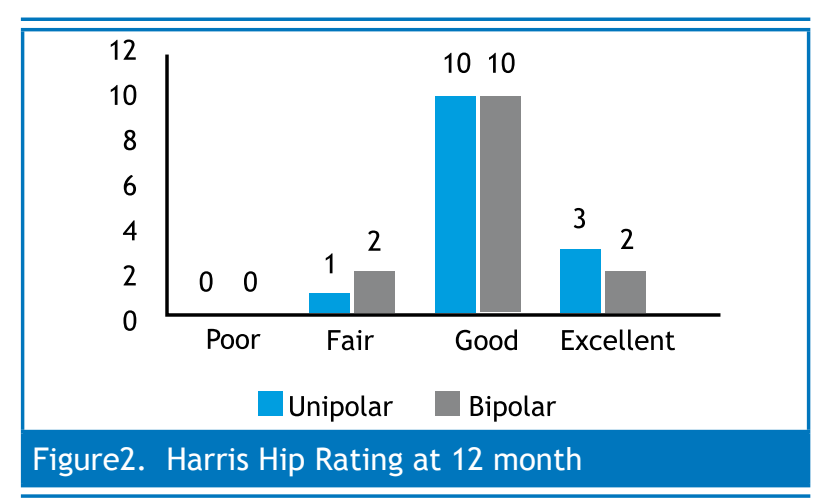

Our study was also unable to prove the theoretical advantages of bipolar prosthesis in terms of functional out come. Elderly patients have less functional demand and they are well satisfied as indoor ambulator. Although the sample size is very small, five patients were community ambulator in unipolar group in comparison to one in bipolar group. A larger trial is necessary to come to a statistically significant conclusion. The other theoretical advantage of bipolar prosthesis was decreased pain during locomotion. We have not tested this advantage as our study was limited to evaluate the functional outcome alone. This aspect may be tested but we believe that if the patient is ambulator pain is well tolerable.

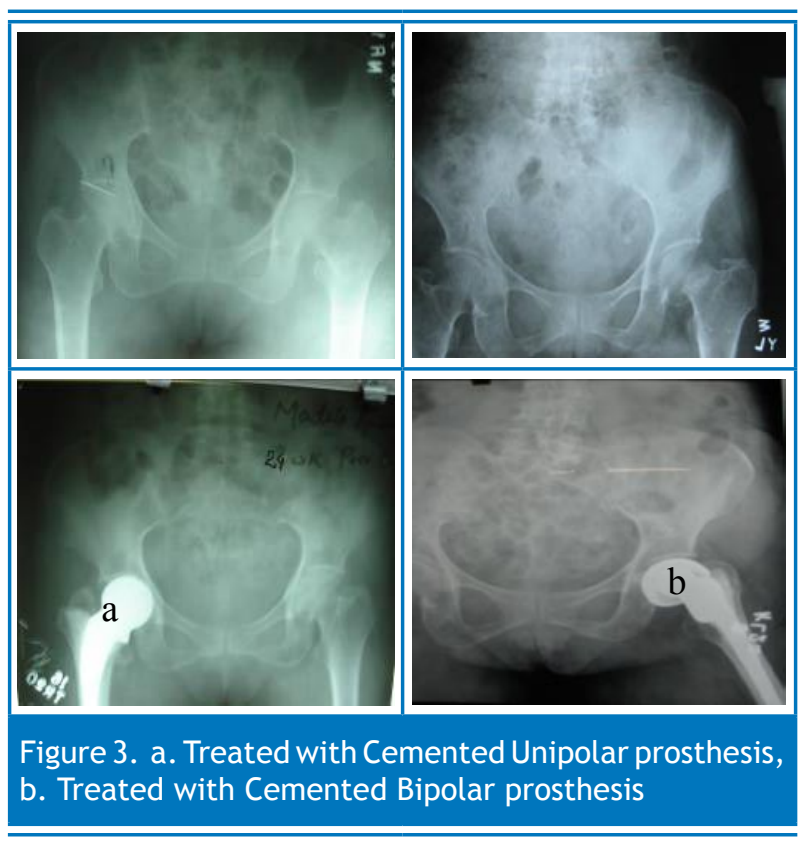

We were very fortunate to have very few complications, $26 \%$ in unipolar group and $20 \%$ in bipolar group, the difference being not statistically significant. Two patients in unipolar group had superficial wound infection which got cured with antibiotics and regular dressing, one had post -operative confusion and giddiness, which was overcome with adequate post-op care and one had a limb length discrepancy of more than $3 \mathrm{~cm}$ which 
Hemireplacement Arthroplasty with Unipolar vs Bipolar Prosthesis for Displaced Hip Fractures in Elderly

was addressed with foot wear raise. In bipolar group, one patient had post-op confusion and giddiness, one had superficial wound infection and one patient had limb length discrepancy of more than $3 \mathrm{~cm}$; they were treated using similar technique as that of unipolar. Less complication may be because of very small sample size of our study.

Cost containment has become a topic of paramount importance especially in poor countries like ours as most elderly people do not earn and have to rely on their family or society or the state to bear the expenses for the treatment. Although cheaper implants of various companies are available in the market, the cheapest unipolar prosthesis cost 3,200 Nepalese Rupees whereas a bipolar prosthesis costs 9,200 . In view of almost one third cost of unipolar prosthesis and similar functional outcome at the end of 12 month follow up, use of unipolar prosthesis for the treatment of hip fractures in elderly is more rational.

\section{CONCLUSIONS}

As early results are similar for both prosthetic groups, use of less expensive unipolar prosthesis for hemiarthroplasty after displaced hip fractures may be justified in the elderly patients.

\section{REFERENCES}

1. Brueton RN, Craig JS, Hinves BL, Heatley FW. Effect of femoral component head size on movement of the two component hemiarthroplasty. Injury. 1993;24:231-5.

2. Drinker H, Murray WR. The Universal proximal femoral endoprosthesis:A short term comparision with conventional hemiarthroplasty. J Bone Joint Surg. 1979:61 A:1167-74.

3. Lanagan P. The Gilberty bipolar prosthesis. A clinical and radiographical review. Clin Orthop. 1979:141:169-75.

4. Phillips TW. The Bateman bipolar femoral head replacement: A fluoroscopic study of movement over a four period. J Bone Joint Surg. 1987:69B:761-4

5. Verbene GHM. A femoral head prosthesis with a built in joint: A radiological study of movement of the two components. J Bone Joint Surg. 1983:65B:544-7.

6. Cornell CN, Levine D, O'Doherty J, Lyden J. Unipolar versus bipolar hemiarthroplasty for the treatment of femoral neck fractures in the elderly. Clin Orthop. 1998;348:67-71.

7. Hudson JI, Kenzora JE, Hebel JR, Gardner JF, Scherlis L, Epstein RS, et al. Eight-year outcome associated with clinical options in the management of femoral neck fractures. Clin Orthop. 1998;348:59-66.

8. Calder SJ, Anderson GH, Jagger C, Harper WM, Gregg PJ. Unipolar or bipolar prosthesis for displaced intracapsular hip fracture in octogenarians. JBone Joint Surg Br. 1996;78:391-4.

9. Kenzora JE, Magaziner J, Hudson J, Hebel JR, YoungY, Hawkes W. Outcome after hemiarthroplasty for femoral neck fractures in the elderly. Clin Orthop. 1998; 348:51-8.

10. Cornell CN, Levine D, O’Doherty J, Lyden J. Unipolar versus bipolar hemiarthroplasty for the treatment of femoral neck fractures in the elderly. Clin Orthop. 1998;348:67-71. 